\title{
CYCLIC AND SECULAR VARIATION IN MICROFOSSIL BIOMINERALIZATION: CLUES TO THE BIOGEOCHEMICAL EVOLUTION OF PHANEROZOIC OCEANS
}

\author{
MARTIN, Ronald E., Geology Dept., U. of Delaware, Newark, DE 19716, U.S.A.
}

The stratigraphic occurrence and mineralogy of major protistan microfossil taxa tend to reflect evolutionary innovation in response to ocean chemistry and fertility. In foraminifera, the characteristic test composition and, in some cases, ultrastructureof each suborder is indicative of the degree of surface ocean $\mathrm{CaCO}_{3}$ saturation, which varied in a cyclic manner through the Phanerozoic, at the time of origin of the suborder. High dissolved phosphate and low $\mathrm{CaCO}_{3}$ saturation in late PrecambrianEarly Cambrian surface waters may have prevented calcification in primitive noncalcareous (organic, agglutinated) foraminiferal stocks.

Scattered reports of coccolithophorid-like microfossils from the Paleozoic are indicative of a secular trend in rising nutrient levels and marine productivity that controlled the initiation of calcareous oozes. Based on acritarch, carbon isotope, and phosphorite records, extremely low nutrient levels ("superoligotrophic" conditions) in Cambrian-to-Devonian seas typically limited population densities of calcareous nannoplankton and prevented the formation of calcareous oozes. The overall "superoligotrophic" surface conditions of the Paleozoic were punctuated by episodes of "catastrophic" eutrophication in the Late Ordovician, Late Devonian, and Late Carboniferous. Following each episode, $\mathrm{CaCO}_{3}$ rain rates were enhanced because Marine C:P (MCP) burial ratios increased permanently above previous levels. Nevertheless, it was not until the Carboniferous that the CCD had deepened sufficiently (via erosion of cratonic limestones) to allow pelagic calcareous oozes to begin to accumulate. Prior to this time, surface waters were sufficiently corrosive (high atmospheric $p \mathrm{CO}_{2}$ ), and the CCD sufficiently shallow, to dissolve virtually all incipient calcareous nannofossils.

Following Late Permian extinctions, plankton re-expanded in response to both eustatic sea level rise (increased habitat availability) and increased nutrient levels ("mesotrophic" conditions). As organic matter and $\mathrm{CaCO}_{3}$ rain rates increased, bioturbation rates also increased, thereby recycling nutrients back to the surface and accentuating productivity and calcareous ooze formation. MCP episodes further accelerated nutrient cycling and productivity in the Neogene, as indicated by the expansion of diatoms, which prefer nutrient-rich ("eutrophic") conditions.

Ironically, catastrophic fluctuations in nutrient levels may have also exacerbated mass extinctions via shortening of pelagic food chains. Nevertheless, re-expansion of the marine biosphere following each extinction episode resulted in a secular trend of increasing biomass and biotic diversity that may have contributed to the decline in background extinction rates through the Phanerozoic. Possibly, this was "immanent" in certain species prior to massive eutrophication, since opportunistic taxa tend to reproduce rapidly, survive extinction, and rediversify in the post-recovery period. 